\title{
Water, heat and solute dynamics of a mud boil, Spitsbergen
}

\author{
Julia Boike $^{\mathrm{a}, *}$, Olaf Ippisch ${ }^{\mathrm{b}, 1}$, Pier Paul Overduin ${ }^{\mathrm{c}, 2}$, \\ Birgit Hagedorn ${ }^{\text {d,3 }}$, Kurt Roth ${ }^{\text {e,4 }}$ \\ a Alfred Wegener Institute for Polar and Marine Research, Telegrafenberg A43, 14473 Potsdam, Germany \\ ${ }^{\mathrm{b}}$ Interdisciplinary Center for Scientific Computing, INF368, University of Heidelberg, 69120 Heidelberg, Germany \\ ${ }^{\mathrm{c}}$ Water and Environment Research Center, University of Alaska Fairbanks, Fairbanks, AK 99775-5860, USA \\ ${ }^{d}$ Quaternary Research Center, University of Washington, Box 351360, Seattle, WA 98195, USA \\ e Institute of Environmental Physics, INF 229, University of Heidelberg, 69120 Heidelberg, Germany
}

Received 17 May 2005; received in revised form 28 October 2005; accepted 9 July 2006

\section{Abstract}

Mud boils, a form of non-sorted circles, cover the ground surface in many periglacial landscapes. The vegetation-covered trough acts as an effective buffer to the downward movement of water and chemicals, while the bare center experiences larger fluxes of heat and mass. Since dissolved ions affect the electric conductivity of the soil solution, measurements of the bulk soil electric conductivity offer potential for estimating solute concentration. Since 1998, bulk soil electric conductivity has been measured automatically and hourly using 32 time domain reflectometry probes over an approximately $1 \mathrm{~m}$ diameter mud boil close to Ny Ålesund, Spitsbergen. Soil water electric conductivity was calculated from bulk soil electric conductivity using volumetric soil water content and a calibration parameter. The seasonal and spatial behaviour of water, temperature and solute concentration within two profiles of this mud boil were analyzed. Concentrations of estimated soil water electric conductivity were highest during the summer period when the active layer was thawed. Thermodynamic equilibrium modelling of the soil solution during freezing suggests that precipitation of dissolved species leads to the observed decrease in electric conductivity. There is a pronounced vertical solute concentration gradient in both profiles, while there is little evidence for horizontal solute concentration gradients beneath the mudboil.

(c) 2007 Elsevier B.V. All rights reserved.

Keywords: Permafrost; Freezing; Geophysical methods; Electric conductivity; Solute dynamics; Patterned ground

\section{(1.}

\section{政}

* Corresponding author. Tel.: +49 331288 2119; fax: +49 331288 2137.

E-mail addresses: jboike@awi-potsdam.de (J. Boike), olaf.ippisch@iwr.uni-heidelberg.de (O. Ippisch), fsppo@uaf.edu (P.P. Overduin), hagedorn@u.washington.edu (B. Hagedorn),

kurt.roth@iup.uni-heidelberg.de (K. Roth).

${ }^{1}$ Fax: +49622154 4404 .

${ }^{2}$ Tel.: +1 907474 2758; fax: +1 9074747979 .

${ }^{3}$ Fax: +12065430489 .

${ }^{4}$ Fax: +496221546405.

\section{Introduction}

Analysis of the phenomenology and dynamic processes of patterned ground yields information on past and present climate and environmental conditions (Washburn, 1979; Romanovskii, 1996). The objective of this study is to characterize (seasonally and spatially) the water and solute dynamics of this heterogeneous system using soil solution sampling, high temporal resolution measurements of bulk soil electric conductivity and 
thermodynamic equilibrium modelling of solution chemistry. This, in turn, adds insight to the mechanical dynamic of the mud boil, and to the discussions on the origin and formation of these periglacial features.

Furthermore, these findings contribute directly to the European Science Foundation project on 'Sedimentary Source-to-Sink-fluxes in Cold Environments'. An understanding of climate processes and their control on mass transfer processes, such as subsurface behaviour of solutes in a mudboil, aids in the understanding of mass export of cold drainage baisins.

\section{Theories of mud boil formation}

Mud boils are symmetric surface features in periglacial environments that have puzzled and fascinated researchers since at least 1900 . Early observations and theories of the origin of patterned ground were the beginning of exciting research. Washburn (1956) summarized and discussed postulations of 19 separate mechanisms of formation for non-sorted circles in particular. These ideas are still central in today's discussions of patterned ground formation.

Mud boils (also known as frost boils, frost scars, mud circles and mud hummocks), classified as non-sorted circles, are found in areas where the ground is subject to seasonal freezing and thawing. They are characterized by a bare, usually doming round mineral soil center, surrounded by vegetation. Some of the mechanisms postulated for their formation are: the sorting of soil materials based on grain size; convection cell like cryoturbation; diapir formation or upwellings of lower soil horizons under pressure (Washburn, 1956). A review of the main mechanisms involved in cryoturbations was presented by Van Vliet-Lanoë (1991) based upon field measurements and micromorphological data. She concluded that "differential frost heaving appears to be the main mechanism of cryoturbation" (pp. 123) and that the presence of organics enhances differential frost heaving. Kessler et al. (2001) modelled sorted circle formation (with barren finer grained circle centers surrounded by stones) from two layers distinct in particle size using a purely mechanical model. The freezing front pushed soil to more compressible soil regions, accumulating in soil plugs that reach to the surface. During thawing, consolidation occurred vertically. The circle was maintained at the surface by the circulation of the stone and fine material domains, upward in the circle center and downward at the edges. Walker et al. (2004) presented horizontal soil profiles across a mud boil. Nutrient concentrations (available potassium, phosphor, nitrogen) and water content declined from the margins toward the center, a trend which they attributed to more 'mechanical' activity towards the center of the boil.

\subsection{Study site}

The Bayelva catchment is located about $3 \mathrm{~km}$ from Ny-Ålesund, Spitsbergen $\left(78^{\circ} 55^{\prime} \mathrm{N}, 11^{\circ} \mathrm{E}\right)$ in the forefield of the Brøggerbreen glacier (Fig. 1A, B). In this region, continuous permafrost underlies coastal areas to depths of about $100 \mathrm{~m}$ and mountainous areas to depths greater than $500 \mathrm{~m}$. The North Atlantic Current warms this area to mean monthly air temperatures around $-13{ }^{\circ} \mathrm{C}$ in January and $5{ }^{\circ} \mathrm{C}$ in July, respectively and provides about $400 \mathrm{~mm}$ annual precipitation mostly as snow between September and May. Our study site is located at about $25 \mathrm{~m}$ above mean sea level, on top of a small hill covered with unsorted circles (Fig. 1C). It is not clear if the mud boils on this hill are currently being degraded (for example, by gelifluction) or maintained by active cryoturbation. Vegetation encroaching from the sides into the mud boil's center - though the centers are still doming - is an indicator for slow mass displacement and semi-active behaviour. While other patterned ground phenomena (such as sorted circles and stripes) are found in the vicinity of the hill, these mud boils are only present on Leirhaugen hill. The mud boils were or are formed under local conditions favourable for mud boil formation after the last glacial period.

Leirhaugen hill is mainly composed of rock, but partly covered by a mixture of sediments: glacial till, finer glacio-fluvial sediments and clay formed by the last glacial advance (Tolgensbakk, personal communication). The gray color of the sediments suggests that the material was deposited by the Kongsfjorden glacier and not the adjacent Brøggerbreen glacier, which deposits redder material. Marine sedimentation could also have contributed since the hill is located below the marine limit (about $38 \mathrm{~m}$ ).

\section{Methods}

We instrumented one of these non-sorted circles (Fig. 1D) in August 1998 to automatically monitor hourly temperature and volumetric liquid water content $(\theta)$. Altogether 32 time domain reflectometry (TDR) probes and 32 temperature probes were installed over the $1 \times 1 \mathrm{~m}$ profile. The position of the TDR probes is shown in Fig. 2. The TDR and temperature data set considered in this study is limited to 1999 , the year in which suction lysimeter data were collected. During installation, soil samples were taken for the analysis of physical parameters. The texture and composition of 25 
134 samples were determined using standard methods. Wet 135 soil was passed through a sieve with $63 \mu \mathrm{m}$ size to 136 measure sand content. After destruction of organics and 137 limestone, silt and clay were separated by sedimentation
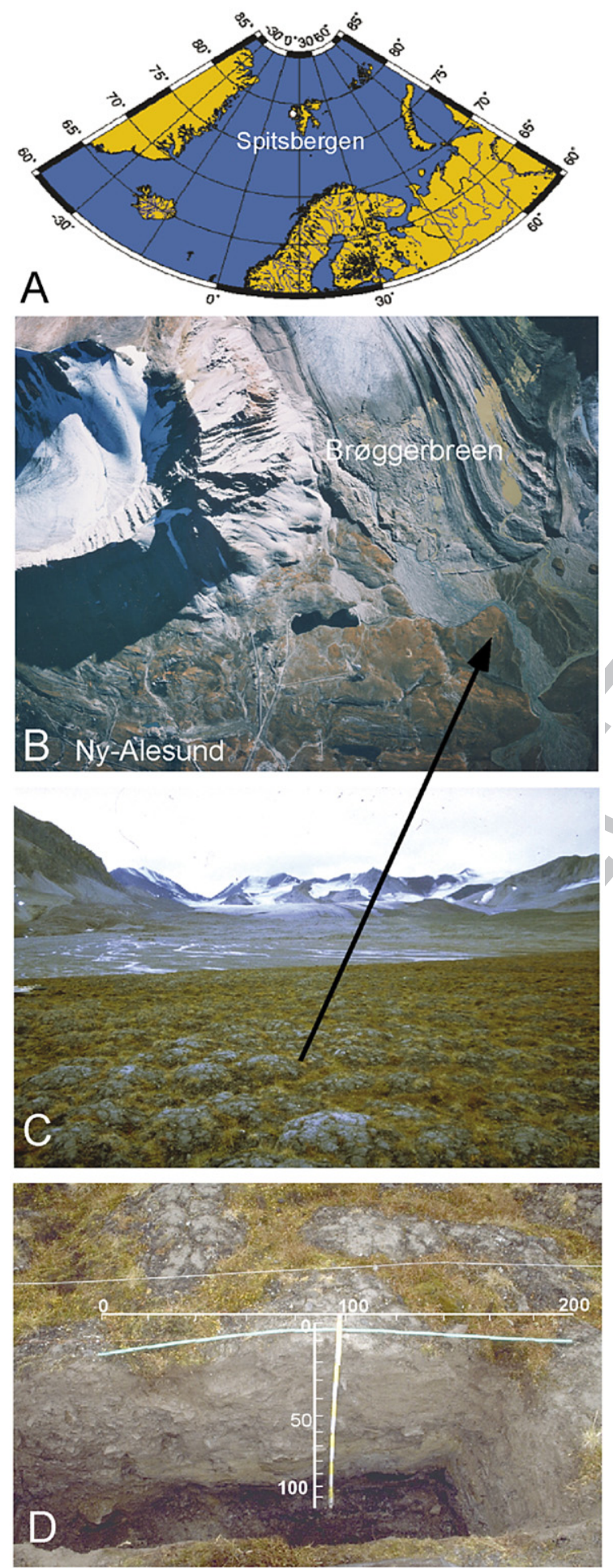

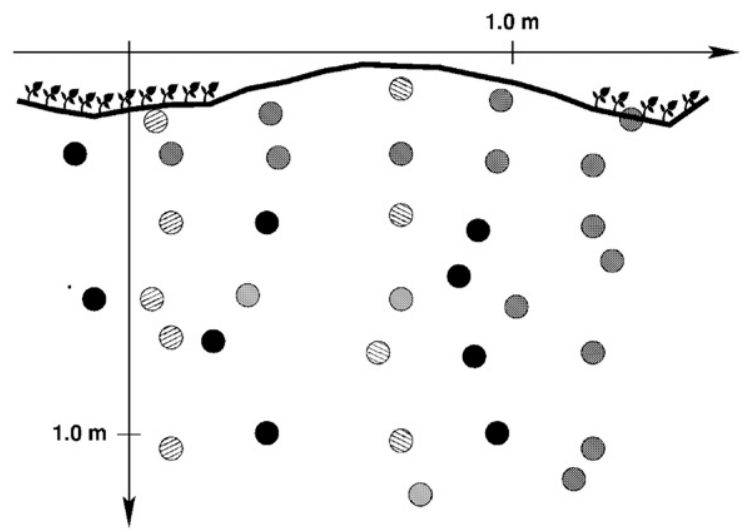

Fig. 2. Position of TDR probes (grey and hatched circles) installed in the mud boil. Temperature probes are installed adjacent to TDR probes. For the analysis, the left profile under vegetation and the profile underneath the center of the mud are used (hatched circles). In addition, nine suction lysimeters (black circles) are installed close to TDR probes (see also Table 1).

in Atterberg cylinders. Soil temperatures were recorded using thermistors calibrated at $0{ }^{\circ} \mathrm{C}$ with a precision of $2.4 \times 10^{-4}{ }^{\circ} \mathrm{C}$ at $0{ }^{\circ} \mathrm{C}$ and an absolute error less than $\pm 0.02{ }^{\circ} \mathrm{C}$ over the temperature range $\pm 30^{\circ} \mathrm{C}$. Volumetric liquid water content was calculated from TDR measurements with an accuracy of 0.02 to 0.005 and a precision better than 0.005 . Soil water was sampled in 1999 using Prenart ${ }^{\circledR}$ suction cups (5 cm long, pore size $2 \mu \mathrm{m}$; Gravquick, Denmark) cups that were installed in 1998 at different depths close to TDR probes. Soil water was analyzed in the field for $\mathrm{pH}$, electric conductivity and alkalinity. The remaining sample water was filtered and stored at $4{ }^{\circ} \mathrm{C}$ in pre-cleaned HDPE bottles until laboratory analysis took place. Cation concentrations were analyzed with ICP-OES (Optima 3000 XL, Perkin Elemer) and anion concentrations were measured with ion chromatograph (Dionex 320).

\subsection{TDR and bulk electric conductivity}

Data on spatial and temporal distribution of water and solutes in frozen and unfrozen soils are essential for energy and mass transport models. A fast method to measure the volumetric water content in situ is TDR.

Fig. 1. The location of Spitsbergen (A) and aerial picture (1:15000) of the area around $\mathrm{Ny}$-Ålesund (B). The study site (arrow) is located on Leirhaugen hill close to end moraines of the Brøggerbreen glacier. Parts of the road network of Ny-Ålesund can be seen in the lower left part of the picture. The Bayelva study site $(\mathrm{C})$ is located in a field covered with non-sorted circles. The excavated mud boil is shown in D. The bare soil circle centers range about $1 \mathrm{~m}$ in diameter and are surrounded by vegetated borders consisting of a mixture of low vascular plants, mosses and lichens. 
160 TDR has become a reliable and widely used technique 161 to measure the water content in frozen and unfrozen 162 soils (for example, Topp et al., 1980; Patterson and 163 Smith, 1980; Roth et al., 1990). The TDR technique for 164 measuring the volumetric water content is based on the 165 large disparity in the relative dielectric permittivities of 166 water and the other soil constituents. The bulk relative 167 dielectric permittivity of the soil determines the velocity 168 with which an electromagnetic wave travels through the 169 soil, so that measurement of the travel time for a known 170 distance allows determination of the material's permit171 tivity. We use a physically-based dielectric mixing model to compute the composite dielectric number of a multiphase mixture using the relative dielectric permittivities and volume fractions of its constituents (Roth et al., 1990).

TDR can also be used to measure the impedance of the bulk soil Z $(\Omega)$, which is related to the bulk soil electric conductivity as a function of time. The bulk soil electric conductivity $\equiv$ urn related to the concentration of ionic solutes (Reluy, 2004) and hence TDR is suited for in situ detection of well-dissociating solutes. The impedance can be determined from the attenuation of an electromagnetic wave traveling along the probe after all multiple
172

173

174

175

176

177

178

179

$180 \mathbf{Q 1}$

181

182

183
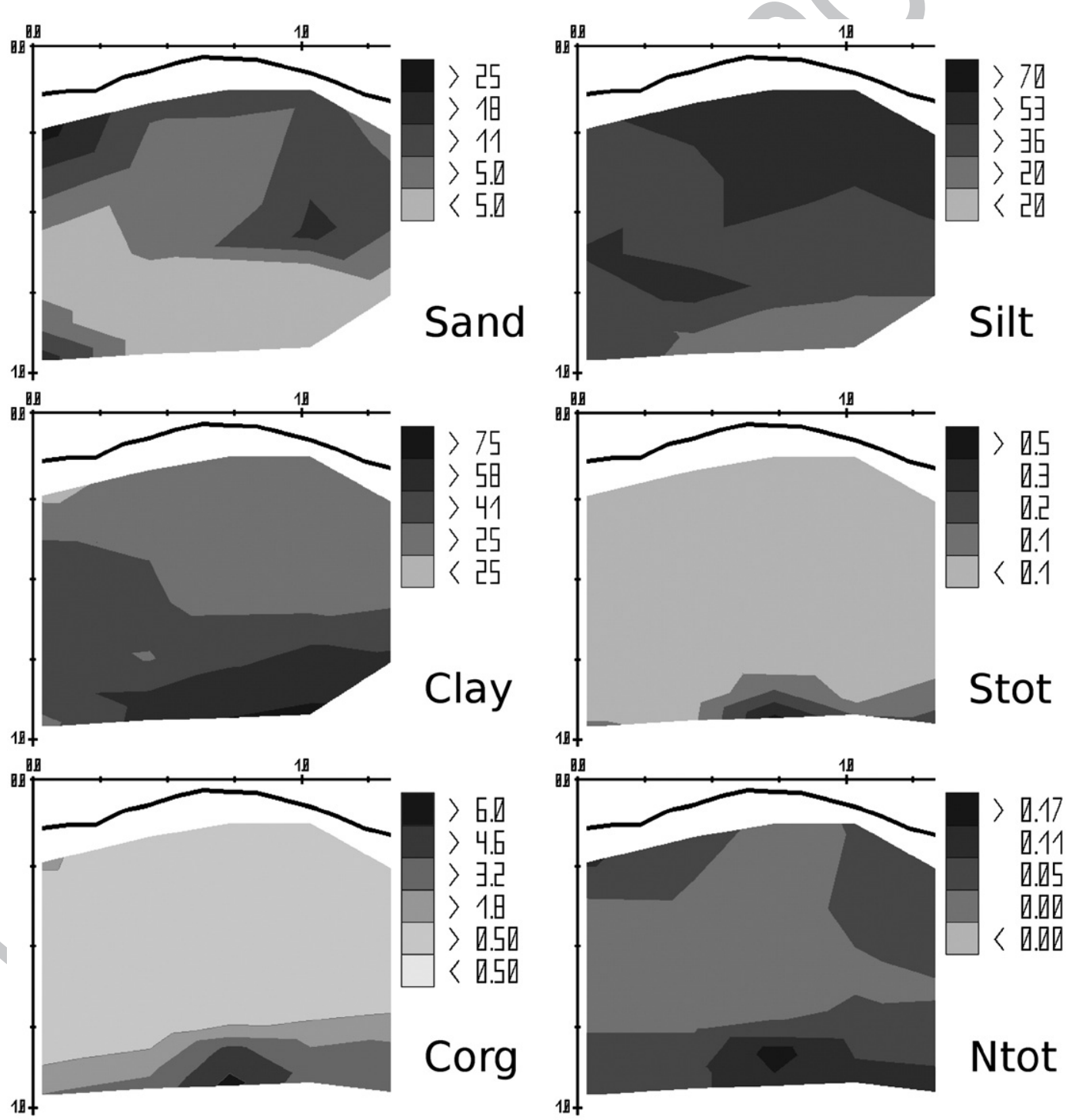

Fig. 3. 2-D distribution of sand, silt, clay and total carbon, nitrogen, sulphur of the mud boil in $\%$ weight. Linear interpolation is used between 25 sampling points. 
184 reflections have ceased and the signal reaches a stable 185 level. Usually it is assumed that the impedance is related 186 to the bulk soil electric conductivity by:

$188 \quad \sigma_{\mathrm{b}}^{25}=\frac{K_{\mathrm{P}}}{Z-Z_{\text {cable }}} f_{\mathrm{T}}$

187 where $\sigma_{\mathrm{b}}^{25}\left[\mathrm{~S} \mathrm{~m}^{-1}\right]$ is the soil bulk electric conductivity 189 corrected to $25^{\circ} \mathrm{C}, K_{\mathrm{p}}\left[\mathrm{m}^{-1}\right]$ is the geometric cell constant 190 of the TDR probe, $Z_{\text {cable }}[\Omega]$ accounts for the total 191 resistance of cables, connectors and cable tester and $f_{\mathrm{T}}[-]$ 192 is a temperature factor defined as:

$193 f_{\mathrm{T}}=1+\alpha(T-25)$

194 where $T\left[{ }^{\circ} \mathrm{C}\right]$ is the soil temperature and $\alpha=0.019^{\circ} \mathrm{C}^{-1}$ is 195 the temperature coefficient (Heimovaara et al., 1995). We 196 calibrated our TDR probes in a range of solutions with 197 known electric conductivities, following the method of 198 Heimovaara et al. (1995). As there was no longer a linear 199 relation between measured impedance and the inverse of 200 the conductivity for high concentrations, we modified 201 Eq. (2) to:

202 $\sigma_{\mathrm{b}}^{25}=\left(\frac{1}{Z-Z_{\text {cable }}}-B\right) K_{\mathrm{p}} f_{\mathrm{T}}$

203 where $B$ is an additional fitting parameter. $B, K_{\mathrm{p}}$ and $204 Z_{\text {cable }}$ were determined by non-linear least squares 205 fitting.

\subsection{Calculation of soil solution electric conductivity $\sigma_{w}$}

The relationship between bulk electric conductivity and the electric conductivity of the liquid phase depends on the conductivity of the solid phase and the geometry of the phases, which is related to soil structure and air, ice and water contents. There are several empirical models, partly with some theoretical justification. Boike and Roth (1997) compared the descriptive power of three models for a permafrost site in Siberia by a comparison of the conductivity measured in water extracted from suction cups with the conductivity predicted from TDR measurements. For the coarse textured soils studied they found the best agreement with a simple regression model:

$\sigma_{\mathrm{b}}=A \theta \sigma_{\mathrm{w}}$

221 where $\sigma_{\mathrm{w}}\left[\mathrm{S} \mathrm{m}^{-1}\right]$ is the electric conductivity of the soil 222 solution, $\theta[-]$ is the volumetric liquid water content of 223 the soil and $A[-]$ is a fitting parameter. For three different mineral soils the parameter $A$ varied between 224 0.7 and 4.8. Best results were obtained with probe specific calibrations. Furthermore, they suggested that $A$ did not change from frozen to unfrozen soils and that this model may be applied to calculate $\sigma_{\mathrm{w}}$ for frozen conditions as well. To our knowledge, the only other model predicting $\sigma_{\mathrm{w}}$ from TDR-determined $\sigma_{\mathrm{b}}$ in frozen soils was introduced by van Loon et al. (1991; also reviewed in Boike and Roth, 1997). This model has been applied for the study of solute dynamics in Swedish field soils (Lundin and Johnsson, 1994) and in frozen lab columns (Stähli and Stadler, 1997) without prior calibration to soil solution electric conductivity. As the model by van Loon et al. (1991) did not predict solution electric conductivity as well as the regression model for permafrost soils in Siberia (Boike and Roth, 1997) we did not consider this model further in this study.

\section{Results}

Soil composition data from the 25 samples taken from the profile is presented in Fig. 3. The soil material generally consists of silty clay with some larger stones. The silt content decreases from over $50 \%$ at the top of the profile to less than $30 \%$ at the bottom, concomitant with an increase of clay content to over $50 \%$ (Fig. 3). Concentrations of organic carbon, total nitrogen and total sulphur are highest at the bottom of the profile, peaking below the mud boil center. Of note are especially high concentrations of organic carbon $(>6 \%$

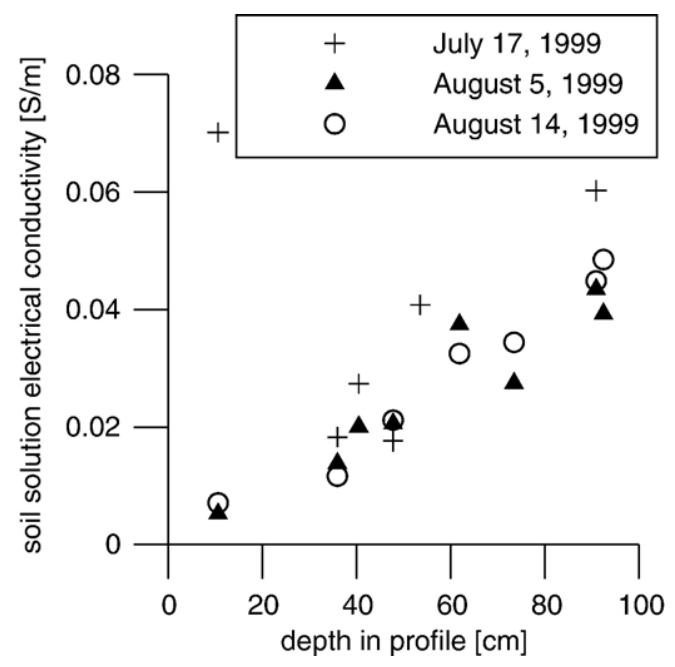

Fig. 4. Soil water electric conductivity obtained from suction lysimeter water at three different times over depth. 
253 weight) at the bottom of the profile. Nitrogen is also

254 elevated below the vegetated trough of the profile.

\section{4.1. Determination of $\sigma w$}

256 The bulk electric conductivity of the soil is generally 257 considered to be the sum of the conductive contributions 258 of the liquid phase and the soil matrix surface

$259 \sigma_{\mathrm{b}}=\sigma_{\mathrm{w}}+\sigma_{\mathrm{s}}$

260 The matrix surface contribution is generally assumed 262 to be low relative to that of the soil solution, and is often 263 neglected (Boike and Roth, 1997). The texture of the soil 264 in this study site is finer and has far more clay than the 265 coarse textured soils studied by Boike and Roth (1997).

266 Since the clay content is high, the conductivity of the solid 267 phase may no longer be negligible and it is not clear if 268 these findings are also valid for this site. To verify this and 269 to calibrate the measurement of $\sigma_{\mathrm{w}}$ we used the measured 270 electric conductivity of water extracted on three dates 271 (July 17, August 5 and 14, 1999) from suction cups 272 installed at nine positions near the TDR probes (Fig. 4). 273 The electric conductivity of the extracted water increased 274 with increasing profile depth, thus the rise of bulk electric 275 conductivity cannot be attributed solely to the increase in 276 finer soil particles.

277 Suction lysimeter data were used to calibrate the 278 model (Eq. (4)). The calculated mean $A$ factors for the 279 regression model are given in Table 1. Calculated $A$ 280 values lie within the same range as the ones calculated by 281 Boike and Roth (1997). Fig. 5 shows a comparison of $\sigma_{w}$ 282 measured in soil water and the corresponding $\sigma_{\mathrm{w}}$ 283 calculated from TDR measurements. Altogether we 284 can see a good linear relation with some outliers. The two 285 water samples with high concentrations were collected 286 during the first sampling and have different ion 287 composition, as will be explained later in the Discussion

\section{t1.1 Table 1}

t1.2 Mean calculated $A$ factors for the linear regression model

t1.3 Suction Suction lysimeter $A$ factor No. of $\mathrm{pH}$ lysimeter location water

\begin{tabular}{lllll} 
& depth $[\mathrm{cm}]$ & \multicolumn{3}{l}{ samples } \\
\hline B1 & 91 & 1.1 & 4 & Neutral, $\mathrm{pH}=7.1$
\end{tabular}

Acidic, $\mathrm{pH}=4.1$ Alkaline, $\mathrm{pH}=7.8$ Neutral, $\mathrm{pH}=7.1$ Alkaline, $\mathrm{pH}=7.9$ Alkaline, $\mathrm{pH}=8.1$ Alkaline, $\mathrm{pH}=7.5$ Alkaline, $\mathrm{pH}=8.0$ Neutral, $\mathrm{pH}=6.7$

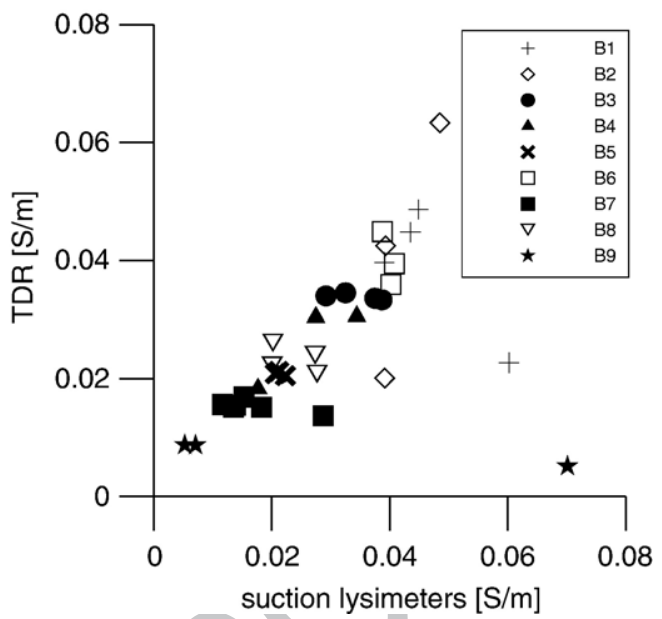

Fig. 5. Soil water electric conductivity obtained from suction lysimeters (names of suction lysimeters in legend) compared to values calculated from bulk electric conductivity (TDR probes) using model (4).

section. A closer examination of the values for individual probes shows a narrow range of conductivities covered by the limited amount of samples taken, so that within the accuracy of the measurements they represent one data point for each probe. This makes verification of the model difficult. However, we assume that there are monotone relations between $\sigma_{\mathrm{w}}$ and $\sigma_{\mathrm{b}}$ and $\theta$ and $\sigma_{\mathrm{b}}$. Therefore the qualitative behaviour of $\sigma_{\mathrm{w}}$ derived from the TDR measurements is expected to be correct even if absolute errors are introduced by disregarding the conductivity of the solid phase.

\subsection{Temperature, volumetric water content and soil solution electric conductivity dynamics}

For the following analysis, we chose two profiles: one located below the vegetated left trough and ther one below the center of the mud boil (Fig. 2).

Fig. 6 shows rainfall and snow depth, soil temperature, soil volumetric water content and $\sigma_{\mathrm{w}}$ at 4 different depths below the vegetated trough. As expected, the probe closest to the surface $(0.06 \mathrm{~m})$ shows higher temperatures and daily temperature fluctuations compared to the lower probes. The temperature signal is attenuated with depth. In May, the snow liquid water content increases considerably, a process also enhanced by rain on snow events (Boike et al., 2003), and infiltration of water rapidly warms the soil at all depths. This is reflected in Fig. 6 by the dramatic increase in the volumetric water content of the soil at successive depths. The liquid water content mirrors most clearly the advance of the thaw front. The phase change ice/water starts during snow ablation and is much enhanced after the snow has ablated. The soil 

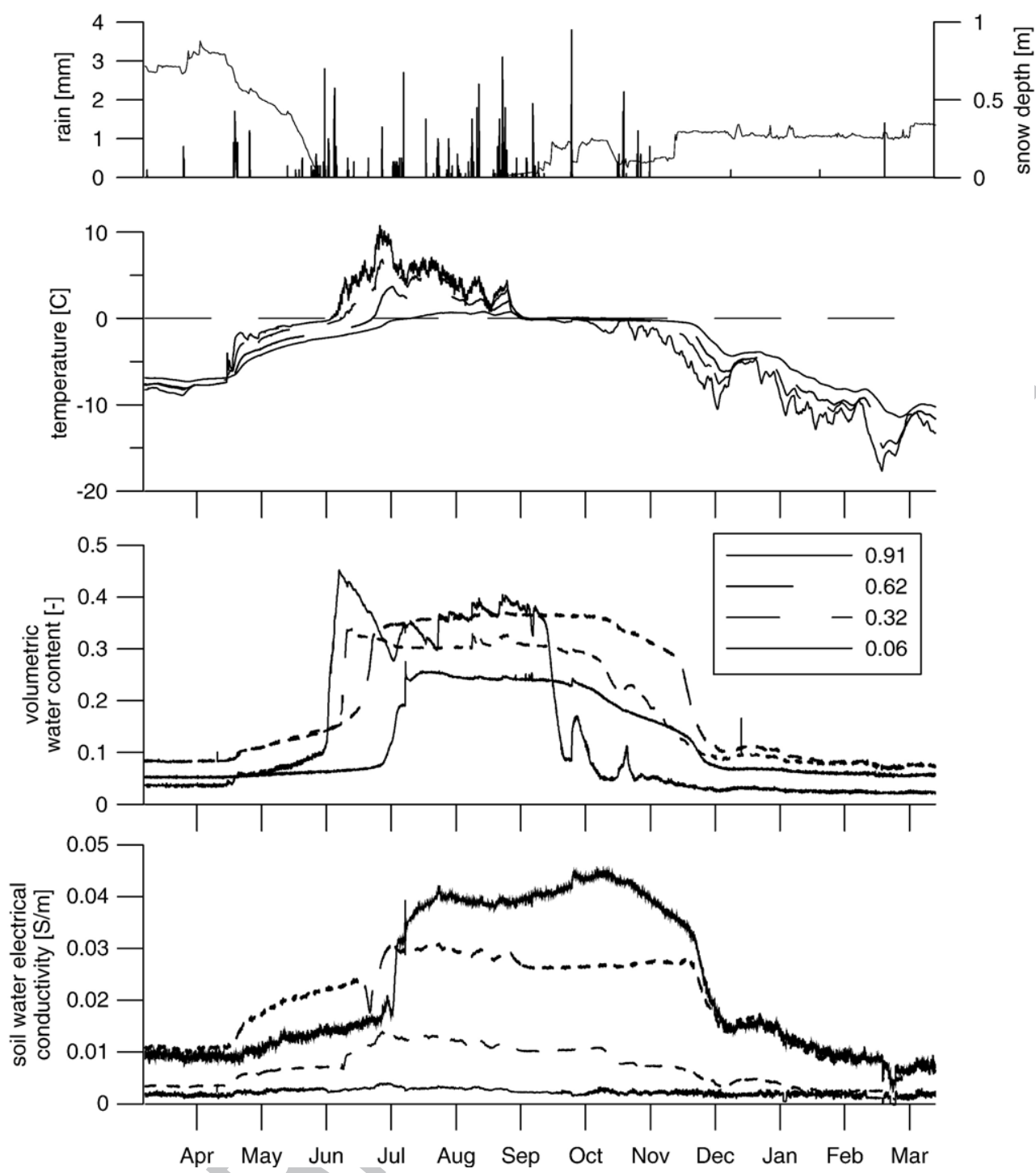

Fig. 6. Rainfall and snow depth, soil temperatures, soil water content and soil water electric conductivity from April 1999 to April 2000 at four depths for a profile underneath the vegetated cover.

319 temperature sensor at $0.91 \mathrm{~m}$ depth passes $0{ }^{\circ} \mathrm{C}$ around the 320 end of July. However, low volumetric water contents $321 \quad(\sim 0.25)$ that remain constant over the summer indicate 322 that the soil is not completely thawed. The temperature

sensor at $1.22 \mathrm{~m}$ depth (not shown in diagram) indicates that the soil never thaws at this depth. During the summer, volumetric water content remains constant at $0.62 \mathrm{~m}$ depth, indicating the perched water table above the frozen ground. Once freezing starts in September, soil temperatures at all depths drop to below zero and phase change from water to ice is initiated ("zero curtain effect"). The phase change is completed by mid-November, after which the soil profile cools. The volumetric liquid water content in these frozen soils during winter ranges between 4 and
$9 \%$ and is lowest at the surface due to desiccation (vapour migration out of the soil, see Roth and Boike, 2001).

The general seasonal behaviour of $\sigma_{\mathrm{w}}$ below the organic (except for the probe nearest to the surface at $0.06 \mathrm{~m}$ ) can be summarized as follows: increase of $\sigma_{\mathrm{w}}$ during thawing, highest $\mathrm{c} \equiv$ trations during the summer and decrease during pall phase change. However, during the spring thaw, the behaviour of $\sigma_{\mathrm{W}}$ is different for each soil depth. At intermediate depth $(0.32 \mathrm{~m}), \sigma_{\mathrm{w}}$ increases during thaw, but continues to increase even after the soil is completely thawed, indicating either transport of solutes to this area or local and continued increases in the concentration of charged solutes. At $0.62 \mathrm{~m}$ depth, a pronounced drop in conductivity occurs
333 
during thaw at about $15 \%$ liquid water content, which indicates that dilution of the soil water has occurred, probably via downward migration of meltwater with lower concentrations of dissolved ionic species. In addition, this is the soil depth with the highest $\sigma_{\mathrm{w}}$ in the frozen soil. Since this is the soil depth that remains thawed longest in the fall (Boike et al., 2003), migration of excluded ions would take place towards this depth. This is also suggested by a small increase of $\theta$ and $\sigma_{\mathrm{w}}$ in December after closure of the zero curtain.

Throughout the whole summer $\sigma_{\mathrm{w}}$ is relatively stable, with small increases of $\sigma_{\mathrm{w}}$ occurring at the three intermediate depths simultaneously with an increase of $\theta$ after a series of rain events during the latter half of
August. However, there is also a peak in $\sigma_{\mathrm{w}}$ measured with the deepest probe at the end of July, which is not connected to a corresponding increase of water content. Only the surface probe shows an increase in $\theta$ at this time, caused by a minor rain event. As the same peak can be recognized at the deepest probe below the mud boil center, it is unlikely to be an artefact and either an in situ increase in solute concentration, for example by dissolution of salts, or lateral inflow must have occurred. Generally in the thawed organic profile, soil water conductivity increases with depth and the highest concentrations occur at the bottom of the profile $(0.91 \mathrm{~m})$.

In the barren soil below the center of the boil the fluctuations of temperature, water content (Fig. 7) and $\sigma_{\mathrm{w}}$
361
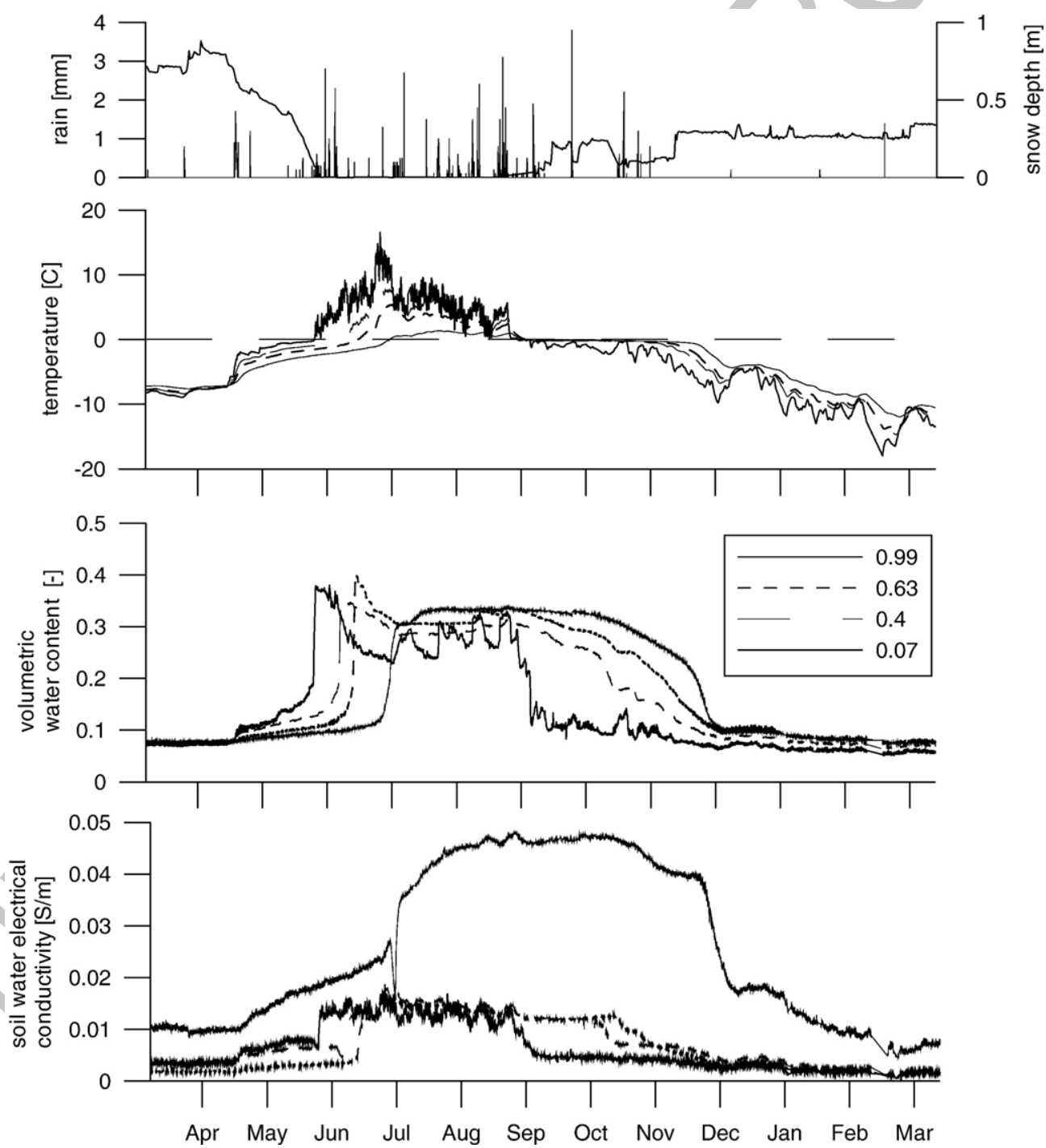

Fig. 7. Rainfall and snow depth, soil temperatures, soil water content and soil water electric conductivity from April 1999 to April 2000 for profile underneath mud. $A=3.8$ in Eq. (4) was used for TDR probe at $0.07 \mathrm{~m}$ under mud. 
375 near the surface are generally higher than below the 376 vegetation covered trough. Due to the lack of vegetation, 377 the profile thaws earlier. In mid-July, the thaw front passes 378 the probe at $0.99 \mathrm{~m}$ depth. Over the course of the summer, 379 the center of the mud boil thaws to greater depth com380 pared to the vegetated trough. The water content of the 381 soil surface layer shows greater fluctuations in response to 382 wetting by rainfall and subsequent drying since these 383 processes are not buffered by vegetation. The $\sigma_{\mathrm{w}}$ values 384 increase with depth in a fashion similar to the profile 385 under the vegetated trough, with highest values of $\sigma_{\mathrm{w}}$ at 386 the bottom of the boil and, $\sigma_{\mathrm{w}}$ values are generally higher 387 at the bottom of the mud profile. Decreases in $\sigma_{\mathrm{w}}$ from the 388 beginning of June $(0.07 \mathrm{~m})$ until the middle of July $389(0.99 \mathrm{~m})$ in the mineral profile indicate the dilution of the 390 soil solution by downward migration of meltwater. As 391 observed for the organic profile, these decreases in soil 392 solution electric conductivity are associated with thawing, 393 but occur before the liquid water content increases.

394 Soil waters from deep suction lysimeters B1 and B2, 395 and from shallower lysimeters B5 and B6, were analyzed 396 for cation and anion concentrations. Based on lysi397 meters B6 and B5 (about $60 \mathrm{~cm}$ ), the most concentrated $398 \equiv$ es are $\mathrm{HCO}_{3}^{-}$and $\mathrm{Mg}^{2+}$ followed by $\mathrm{Ca}^{2+}>$ $399 \mathrm{~S}^{2}>\mathrm{SO}_{4}^{-2}>\mathrm{Cl}^{-}>\mathrm{K}^{+}>\mathrm{NO}_{3}^{-}$. Ionic concentrations at $\mathrm{B} 6$, 400 beneath the center of the mud boil are generally higher 401 than at B5, beneath the vegetated trough, with exception 402 of $\mathrm{NO}_{3}^{-}$and $\mathrm{Si}_{\mathrm{aq}}$. The deeper soil solutions (around $403100 \mathrm{~cm}$ ) are closer to the permafrost table and were 404 most concentrated in $\mathrm{SO}_{4}^{2-}$, followed by $\mathrm{Mg}^{2+}>\mathrm{Ca}^{2+}>$ $405 \quad \mathrm{HCO}_{3}^{-}>\mathrm{Si}_{\mathrm{aq}}=\mathrm{K}^{+}=\mathrm{Cl}^{-}$. The first samples collected from 406 B2 in July 1999 show very low pHs of 4, higher Fe $407\left(20-40 \mu \mathrm{g} \mathrm{L}^{-1}\right)$ and very high $\mathrm{Al}_{\mathrm{aq}}\left(1-2 \mathrm{mg} \mathrm{L}^{-1}\right)$ 408 concentration compared to later samples. A possible 409 inorganic mechanism leading to such a low $\mathrm{pH}$ in natural 410 water is dissolution of pyrite. Two possible overall redox 411 reactions are given below (Langmuir, 1997, pp. 458):

$412 \mathrm{FeS}_{2}+7 / 2 \mathrm{O}_{2}+\mathrm{H}_{2} \mathrm{O} \rightarrow \mathrm{Fe}^{2+}+2 \mathrm{SO}_{4}^{2-}+2 \mathrm{H}^{+}$

413

$\mathrm{FeS}_{2}+14 \mathrm{Fe}^{3+}+8 \mathrm{H}_{2} \mathrm{O} \rightarrow 15 \mathrm{Fe}^{2+}+2 \mathrm{SO}_{4}^{2-}+16 \mathrm{H}^{+}$ coal are located nearby. The low $\mathrm{pH}$, occurrence of coal and enrichment in Fe all support dissolution of pyrite as a common cause. The low $\mathrm{pH}$ enhances chemical weathering and therefore contributes to the overall increase in solute concentration at depth.

The rapid decrease in $\sigma_{\mathrm{w}}$ when soils freeze (Figs. 6 and 7) is counter-intuitive, since an increase in concentration due to the exclusion of ions during freezing is expected. A first approach to model the change in solute composition and concentration of soil wa $\equiv$ subfreezing temperatures can be performed with gechemical equilibrium model FREZCHEM62 (Marion and Grant, 1994). This program is written to model changes in chemistry during stepwise freezing of a water solution and considers either continuous contact between solution and precipitated phase or fractional removal of precipitated phase from solution. It does not incorporate soil physical factors like mineral, organic or colloid surfaces that most likely contribute to changes in water chemistry. However, it allows estimation of the chemical development of a solution during freezing. Results of the modelling with FREZCHEM of solutions B1 and B6 collected at 1 and $0.6 \mathrm{~m}$ depth is shown in Fig. 8. Liquid water content rapidly decreases below subfreezing temperatures and at $-5{ }^{\circ} \mathrm{C}$ only $0.006 \%$ of the total water content present before freezing is still unfrozen. During freezing salts of different composition precipitate from solution in the sequence: $\mathrm{CaSO}_{4} \cdot 2 \mathrm{H}_{2} \mathrm{O}$, $\mathrm{MgCO}_{3}, \mathrm{CaMg}\left(\mathrm{CO}_{3}\right)_{2}, \mathrm{~K}_{2} \mathrm{SO}_{4}$, and $\mathrm{Na}_{2} \mathrm{SO}_{4} \cdot 10 \mathrm{H}_{2} \mathrm{O}$. The precipitation of these salts causes the changes in molar elemental ratios displayed in Fig. 8. The most striking difference between the soil solution with high $\mathrm{SO}_{4}^{2-}$ concentration $(\mathrm{B} 1, \mathrm{~B} 2)$ and high $\mathrm{HCO}_{3}^{-}$concentration (B6) is in the change of $\mathrm{Na} / \mathrm{Cl}$ ratios. While in the $\mathrm{B} 1$ soil solution the $\mathrm{Na} / \mathrm{Cl}$ ratio constantly increases, it decreases in $\mathrm{B} 6$ due to the formation of $\mathrm{KCl}$ at $-10{ }^{\circ} \mathrm{C}$. Compared to TDR measurements, the calculated liquid water content based on water chemistry is much lower, a difference amounting to up to $9 \%$ by volume. An important part of liquid water in frozen soils exists as thin water films on particle surfaces (Ugolini and Anderson, 1973), and such water-surface interactions are not considered in FREZCHEM. If surface-bound water is not in contact with the solute-rich solution excluded from the forming ice, then the predicted precipitation of salts due to freezing would hold. Measurements of $\sigma_{\mathrm{w}}$ depend on a direct current pathway between electrodes (in this case, TDR sensor wave guides), so that isolated pockets of high concentration will not contribute to the measured bulk electric conductivity of the soil. Surface bound water, however, contributes to the measurement of $\sigma_{\mathrm{b}}$ (Guy-Chapman double layer theory). 

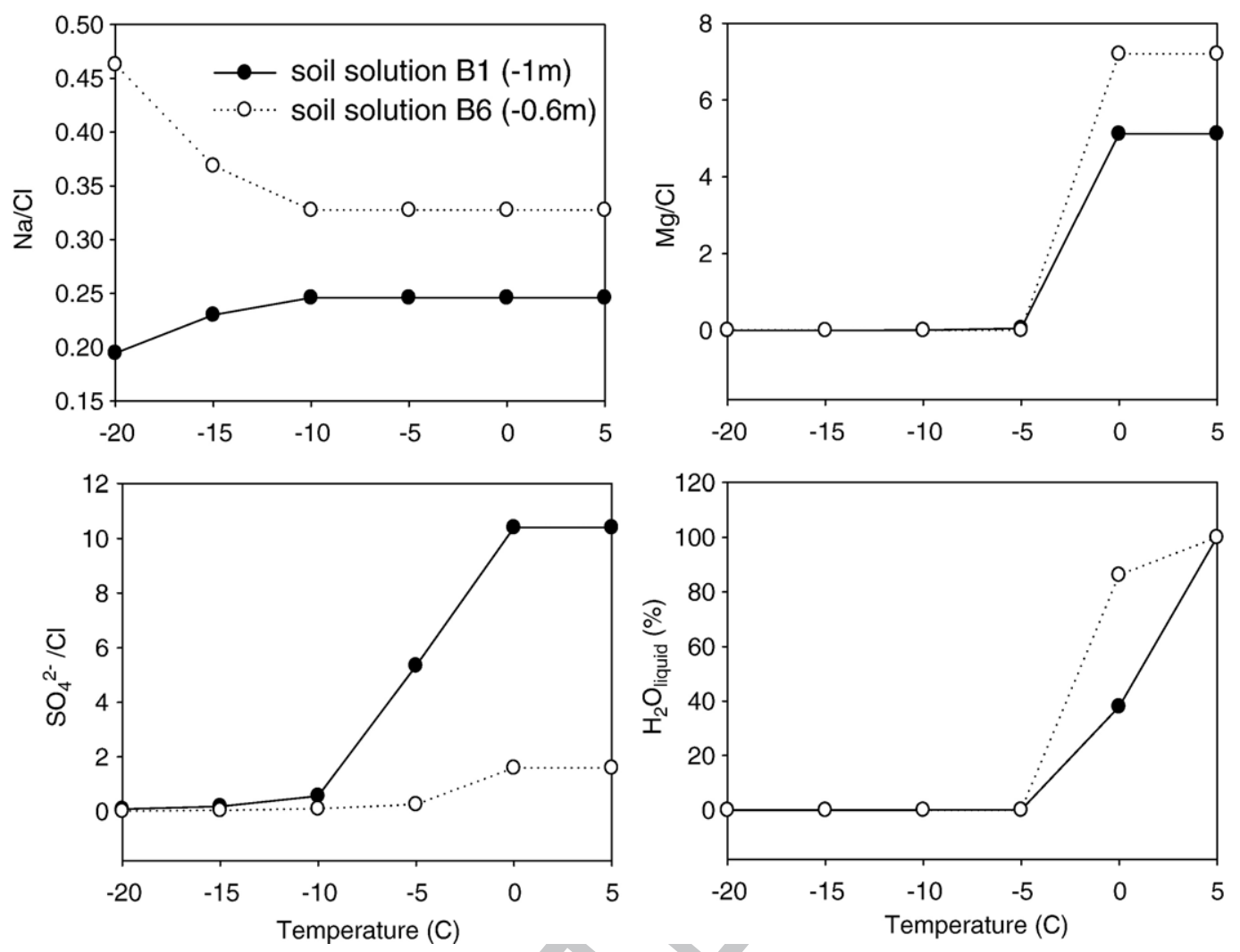

Fig. 8. Molar element ratios and liquid water concentration (\%) modelled with FREZCHEM62 between +5 and $-20^{\circ} \mathrm{C}$. The soil solutions are taken from suction cups B6 and B1. Changes in element ratios indicate formation of solid salt precipitates that remove specific elements from solution. Liquid water content refers to percent of liquid water of total amount of water that was present before freezing. At $-20^{\circ} \mathrm{C}$ liquid water content is less than thper mille.

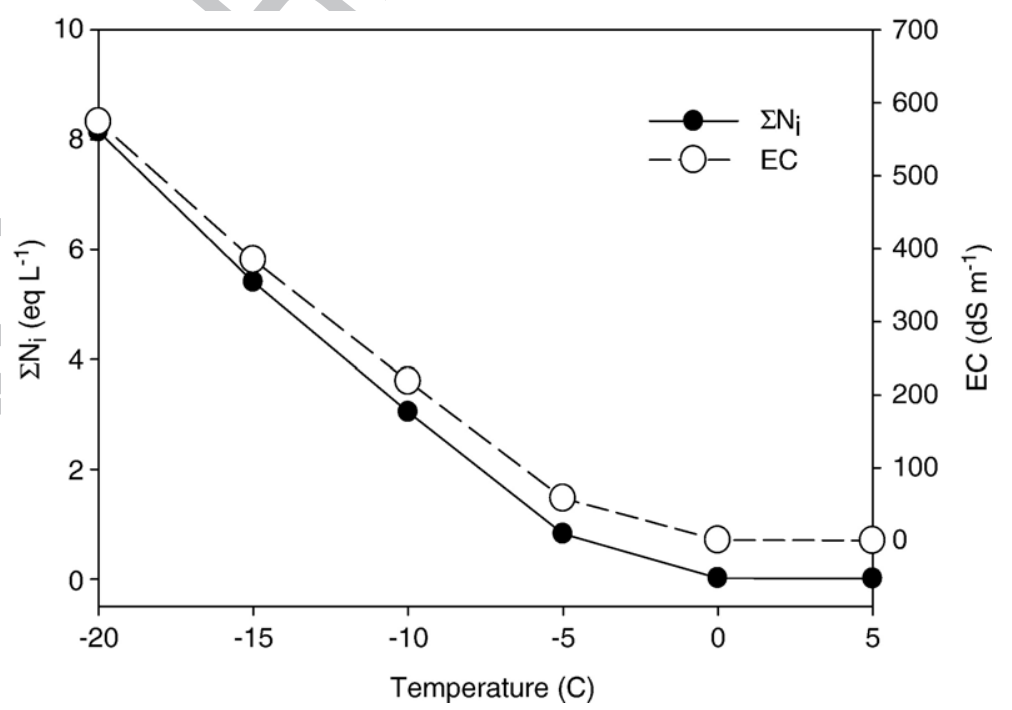

Fig. 9. Calculated total ion concentration in eq $\mathrm{L}^{-1}$ in remaining solution during freezing. EC is calculated from Eq. (8) using total ion activity (eq/I $\left(\sum a_{\mathrm{i}}=\sum N_{\mathrm{i}} \gamma_{\mathrm{i}}\right.$ where $\gamma_{\mathrm{i}}$ is the activity coefficient provided by FREZCHEM62) instead of ion concentration $N_{\mathrm{i}}$. 
To compare the modelled solution with measured 477 conductivity, the electric conductivity is calculated 478 following the approach of Reluy et al. (2004) relating 479 electric conductivity (EC) to the equivalent concentra480 tion of ions in solution $\left(\sum N\right)$. The relation between EC 481 and $\sum N$ is given by:

$482 E C=10^{-6} u^{\prime} F \sum_{\mathrm{i}} N_{\mathrm{i}}$

483 where $F$ is Faraday's constant $\left(\mathrm{Cmol}^{-1}\right)$, and $u^{\prime}$ is the 484

$485 u^{\prime}=\frac{\sum_{\mathrm{i}} N_{\mathrm{i}} u_{\mathrm{i}}}{\sum_{\mathrm{i}} N_{\mathrm{i}}}$

486 where $u_{\mathrm{i}}$ is the limiting equivalent ionic mobility of ion $\mathrm{i}$ $487\left[\mathrm{mS} \mathrm{cm}^{2} \mathrm{~mol} \mathrm{eq}^{-1} \mathrm{C}\right.$ calculation we used values of $u_{i}$ Q2 488 given in Table 3 ith 489 normalities, $N_{\mathrm{i}}$, we used the activities calculated with 490 FREZCHEM for each ion and ion pair. The results of this 491 calculation are shown in Fig. 9, indicating that the solution 492 electric conductivity increases with increasing solute 493 concentration from around $0.05 \mathrm{~S} \mathrm{~m}^{-1}$ to $60 \mathrm{~S} \mathrm{~m}^{-1}$. 494 The total concentration of ions in the remaining unfrozen 495 solution increases by a factor of $\sim 1000$, whereas without 496 precipitation of salts the concentration would increase by a 497 factor of $\sim 17000$ at the final water content. Modelled 498 changes to soil solution, in the absence of mineral-soil 499 solution interactions, lead to a predicted increase in soil 500 water electric conductivity of three orders of magnitude 501 with freezing. The water electric conductivities in the 502 thawed soil estimated for the solution analyzed here are of 503 the same order of magnitude as those predicted by this 504 model (e.g. for a measured solution electric conduc505 tivity of $0.038 \mathrm{~S} \mathrm{~m}^{-1}$, we predict an electric conductivity 506 of $0.050 \mathrm{~S} \mathrm{~m}^{-1}$ ).

507 If the contribution of the clay particle surface 508 conductivity to $\sigma_{\mathrm{b}}$ is significant, the isolation of clay 509 particles by ice layers could be another reason for the 510 reduction of $\sigma_{\mathrm{b}}$. In that case $\sigma_{\mathrm{w}}$ in frozen soil might be 511 underestimated by the values calculated from bulk 512 electric conductivity measured with the TDR probes.

\section{5. Discussion}

514 5.1. Observed changes in soil water electric conductivity 515 with time events. Using the model of Boike and Roth (1997), we show that the largest annual increase and decrease are associated with thawing and freezing, respectively, of the soil. During thaw, for both soils under the boil and the vegetated trough, soil water electric conductivity at all depths decreases by up to $30 \%$ before the increase associated with thawing occurs. The thaw increase occurs simultaneously with the increase in liquid water content associated with the phase change of ice to water. We suggest that the initial decrease in electric conductivity indicates that the infiltration and refreezing of snow meltwater has diluted the available soil solution.

\subsection{Increase in solute concentration with depth}

Our data show that soil solutes within the mud boil are stratified horizontally throughout the year and that this stratification, with highest concentrations at the bottom of the profile, is dominant over any vertical stratification (org $\equiv$ versus mud). Lundin and Johnsson (1994) also found that $\sigma_{\mathrm{w}}$ increased with depth and percentage of fines in Swedish agricultural soils. Alekseev et al. (2003) and Kokelj and Burn (2003) also find the highest concentrations in the soil profile at the boundary between seasonally thawed soil and permafrost. Alekseev et al. (2003) conclude that permafrost landscapes in general accumulate solutes at the upper boundary of the permafrost, ating as a geochemical barrier.

In addition to this depth stratification, we observe a slight increase in soil electric conductivity beneath the center of the mud boil. Depressions, as in our case the bowl-shaped region beneath the mud boil, have even higher concentrations of solutes. These subtle variations in concentration might be the initiator of irregularities in the permafrost table due to the depression of the freezing point and thus, the precursor of certain patterned ground, such as these non-sorted circles. Once a bowlshaped depression of the permafrost table exists, celllike circulation pattern within the active layer can be initiated (i.e. the equilibrium model after Mackay, 1980). However, Fig. 8 shows that the depression of the freezing point by solute exclusion from a freezing solution with the chemistry of extracted soil water is only sufficient to maintain less than $0.1 \mathrm{~mL}$ of water in the liquid state per liter of soil solution below $-10{ }^{\circ} \mathrm{C}$, implying that the effect of solute exclusion on the permafrost table depth are minimal compared to those of differences in surface cover and overlying soil thermal properties. Therefore it seems plausible that differential frost heave is respensible for the formation of the mud 
568 boils as also stated by Van Vliet-Lanoë (1991). Walker 569 et al. (2004, pp. 178) postulated that frost boils typical of 570 coastal areas pump solutes to the surface as a result of 571 relatively high evaporation rates and that the salts thus 572 deposited inhibit vegetation growth. In contrast to these 573 findings, our data suggest that net accumulation of 574 solutes occurs at the base of the active layer, with little 575 difference between mud boil and adjacent vegetated 576 regions. In both profiles, the highest values of $\sigma_{\mathrm{w}}$ occur 577 at depth, whereas the lowest values are found in the 578 upper coarser horizon.

579 The increase with depth probably results from one or 580 both of two general processes. First, seasonal freezing 581 may lead to a cumulative downward migration of solutes 582 as a result of solute exclusion from the freezing soil 583 water. This downward migration is ultimately limited by 584 the presence of the permafrost table, which provides a 585 natural boundary to downward percolation. Secondly, 586 the fraction of finer material increases with depth at this 587 site providing a higher surface area susceptible for 588 chemical weathering.

\subsection{Comparison to thermodynamically modelled freezing}

The high temporal resolution of soil water electric conductivity data derived from TDR measurements permits qualitative identification of processes such as dilution (melting of pure ice) $\equiv$ ncentration in frozen soil during snow ablation and $\bar{m}$ mration in the thawed soil. These are in congruence with the observed hydrologic and thermal dynamic. However, the absolute concentration values during the frozen period are much lower than expected if exclusion of solutes from the freezing soil solution occurs, despite the fact that thermodynamically modelled freezing indicates that several salts precipitate from soil solution during freezing. The time difference between the increase in water content and soil water electric conductivity during thawing might indicate kinetic delay of re- $\equiv$ lution of these salt crystals. Furthermore, some of precipitates, like carbonates and Ca-sulfates, may not re-dissolve completely. The higher amount of particulate inorganic carbon found at depth of mud boil may be a direct result of precipitation of fine carb $\equiv$ s combined $\risingdotseq$ mechanical movement of fines to botrom of mudच̃ol. The contribution of solute movement is unlikely since it would be against the concentration gradient.

The calculation of electric conductivity from salt concentration and salt composition strongly depends on ion mobility. However, values used for $u_{i}$ have been determined for temperate solutions. Subfreezing temperatures and changes in the viscosity of water may decrease ion mobility and electric conductivity. Further experimental investigations are needed to determine mobilities of single ions and ion pairs at temperature below $0{ }^{\circ} \mathrm{C}$. Furthermore, water bound to clay particle and ice surfaces may have lower solute concentrations than regions containing solutes excluded from freezing pore water, leading to lower overall measured salt concentration per unit volume of soil. Ostroumov et al. (2001) found that liquid drops on the surface of the forming ice were probably responsible for solute transport in frozen deposits close to the freezing front. The implication is that excluded solutes are restricted to small, unconnected domains within the soil that would not contribute to measured bulk soil electric conductivity.

\subsection{Implications for cryoturbation}

Walker et al. (2004) hypothesize that particles and dissolved organic material are carried downward at the margins of frost boils by soil movement a $\equiv$ aching, whereas organics accumulate in the thawed $\overline{\overline{A T}}$ the frost boil. At the center of the mud boil, upward migration of organics occurs. The high concentrations $(>6 \%)$ of organic carbon in our mud boil (Fig. 2) support their hypothesis. The differences in thermal and hydrologic regime, thaw depth, and total nitrogen, organic carbon and total sulfur concentrations between mud and vegetated trough profiles create a physically different environment. This, in turn, affects the vegetation and possibly governs the mechanical forces that create the mud boils. Cryoturbation is the most effective process in moving organics and (weathered) minerals upwards from the bottom of the active layer, thus counteracting the downward fluxes. Cryoturbation is likely to change with a changing climate. On Svalbard, mean annual ground surface temperature currently increases at a rate of $\sim 0.4{ }^{\circ} \mathrm{C}$ per decade (Isaksen et al., 2001).

\section{Conclusion}

The influence of mud boils on solute migration is small compared to the influence of the seasonal freeze-thaw cycle in the presence of permafrost. The soil solution electric conductivity increases with depth beneath a mud boil, irrespective of lateral position, but seasonal changes in conductivity between frozen and thawed soil are up to 5 times greater. TDR-determined bulk electric conductivity is a useful tool, since it permits high temporal resolution measurement of changes in soil electric conductivity, and thus a means of investigating solute dynamics. The deviation between TDR determined and thermodynamically modelled changes in soil solution chemistry
654 655 656 657 658 659 660 661 662 663 
666 identifies two future research goals: (i) a new model 667 accounting for changes in phase geometry during freezing 668 and (ii) including the effects of soil surface physics in 669 thermodynamic models of freezing.

\section{Acknowledgements}

671 We gratefully acknowledge financial support from 672 the Deutsche Forschungsgemeinschaft (DFG), the 673 European Union and a research grant awarded to Julia 674 Boike by the Deutsche Akademie der Naturforscher 675 Leopoldina. Essential logistic and technical support was 676 provided by the German and the Norwegian Research 677 Stations in Ny-Ålesund and by Christian Wille and 678 Molo Stoof. Thanks to Antje Eulenburg for analyzing 679 the water samples. Discussions with Hugh French 680 during the 2nd Workshop Shifting Lands - New 681 Insights Into Periglacial Geomorphology in France 682 motivated this contribution.

\section{References}

684 Alekseev, A., Alekseeva, T., Ostroumov, V., Siegert, C., Gradusov, B.,
Mackay, J.R., 1980. The origin of hummocks, western Arctic coast. Can. J. Earth Sci. 17 (8), 966-1006.

Marion, G.M., Grant, S.A., 1994. FREZCHEM: A chemicalthermodynamic model for aqueous solutions at subzero temperatures. Hanover, NH, Cold Regions Research and Engineering Laboratory, U.S. Army Corps of Engineers.

Ostroumov, V., Hoover, R., Ostroumova, N., Van Vliet-Lanoe, B., Siegert, C., Sorokovikov, V., 2001. Redistribution of soluble components during ice segregation in freezing ground. Cold Reg. Sci. Technol. 32, 175-182.

Patterson, D.E., Smith, M.W., 1980. The use of time domain reflectometry for the measurement of unfrozen water content in frozen soils. Cold Reg. Sci. Technol. 3, 205-210.

Reluy, F.V., de Bécares, J.M., Hernandéz, R.D., Díaz, J.S., 2004. Development of an equation to relate electric conductivity to soil and water salinity in a Mediterranean agricultural environment. Aust. J. Soil Res. 42, 381-388.

Romanovskii, N.N., 1996. Periglacialial processes as geoindicators in the cryolithozone. In: Berger, A.R., Iams, W.J. (Eds.), Geoindicators: Assessing Rapid Environmental Changes in Earth Systems. Rotterdam, Balkema. 47-68 pp.

Roth, K., Boike, J., 2001. Quantifying the thermal dynamics of a permafrost site near Ny-Ålesund, Svalbard. Water Resour. Res. 37 (12), 2901-2914. doi:10.1029/2000WR000163.

Roth, K., Schulin, R., Flühler, H., Attinger, W., 1990. Calibration of time domain reflectometry for water content measurement using a composite dielectric approach. Water Resour. Res. 26 (10), 2267-2273.

Stähli, M., Stadler, D., 1997. Measurement of water and solute dynamics in freezing soil columns with time domain reflectometry. J. Hydrol. 195, 352-369.

Topp, G.C., Davis, J.L., Annan, A.P., 1980. Electromagnetic determination of soil water content: measurements in coaxial transmission lines. Water Resour. Res. 3 (16), 574-582.

Ugolini, F.C., Anderson, D.M., 1973. Ionic migration and weathering in frozen Antarctic soil. Soil Sci. 115, 461-470.

van Loon, W.K.P., Perfect, P.H., Groenevelt, P.H., Kay, B.D., 1991. Application of dispersion theory to time domain reflectometry in soils. Transp. Porous Media 6, 391-406.

Van Vliet-Lanoë, B., 1991. Differential frost heave, load casting and convection: converging mechanism; a discussion of the origin of cryoturbations. Permafr. Periglac. Process. 2, 123-139.

Walker, D.A., Epstein, H.E., Gould, W.A., Kelley, A.M., Kade, A.N., Knudson, J.A., Krantz, W.B., Michaelson, G., Peterson, R.A., Ping, C.-L., Raynolds, M.K., Romanovsky, V.E., Shur, Y., 2004. Frostboil ecosystems: complex interactions between landforms, soils, vegetation and climate. Permafr. Periglac. Process. 15, 171-188.

Washburn, A.L., 1956. Classification of patterned ground and review of suggested origins. Bull. Geol. Soc. Am. 67, 823-866.

Washburn, A., 1979. Geocryology - a survey of periglacial processes and environments. Edward Arnold, London. 406 pp.
712 